\title{
The Bacterial Nucleoid
}

\author{
By KJELL KLEPPE, STEINAR ÖVREBÖ AND IVAR LOSSIUS \\ Department of Biochemistry, University of Bergen, Bergen, Norway
}

This article deals with some aspects of the structure of the nucleoid in Escherichia coli. It is based on a contribution to the symposium on 'Relations between Structure and Function in the Prokaryotic Cell' at the Annual Meeting of the Society for General Microbiology in April 1978, but was not published in the Symposium Volume.

One of the main features that distinguishes a prokaryotic cell from a eukaryotic cell is the absence of a nuclear membrane. Nuclear-like bodies in bacteria were first observed using the light microscope and DNA-specific stains such as the Feulgen or Giemsa stains (see Bisset, 1970 , for references). Phase contrast microscopy as well as fluorescence microscopy have also been used to visualize the nucleoid. Some results obtained by Mason \& Powelson (1956), employing a high concentration of gelatin in the medium to increase the phase contrast within the bacteria, are shown in Fig. 1. Under these conditions, using phase contrast microscopy, the nucleoids appear as dark bodies, sometimes rod shaped, against a white background. Nuclear bodies are clearly seen at different stages in the cell cycle. Parts of newly formed daughter chromosomes are also visible.

Somewhat similar results have recently been obtained by Hecht et al. (1975) employing ethidium bromide and by Bisset \& Whitby (1978) using the fluorescent stain acridine orange. In the latter case, the dividing nucleoids of enterobacteria such as Escherichia coli were found to be in pairs, often oriented as if dividing with the long axis. In contrast, the nucleoids of Bacillus cereus were also found in pairs, but lying parallel to the long axis.

Advances in the understanding of the morphology of the bacterial nucleus came with the use of the electron microscope which clearly revealed the absence of a nuclear membrane (see Bisset, 1970, for references). The type of nucleus found in prokaryotic cells has been referred to as a nucleoid (meaning nucleus-like), nuclear body, nuclear equivalent or chromatin body. If one examines a thin section of the Gram-negative bacterium $E$. coli in the electron microscope (Fig. 2) one can see areas within the cell which are less electron dense than the surrounding cytoplasm and membrane; these areas are presumably densely packaged DNA. Depending on the method of fixation and magnification, bundles of fibres may also be seen and these are thought to be DNA fibres (Ryter, 1968). The nucleoid occupies a predominantly central position in the cell but its shape may often seem quite irregular and give the illusion of isolated small bodies. Serial sections, however, show that all such regions are continuous with a larger body and this body is often seen attached to the cytoplasmic membrane. One reason for the irregularity often seen is probably that the transcriptionally active regions are covered with ribosomes and thus these areas will be darker than the non-active regions of the chromosome. The light areas of the cell, therefore, probably only indicate the non-active regions of the chromosome. The DNA itself represents only 2 to $3 \%$ of the weight of the cell. However, the volume it occupies is considerably greater. In Grampositive cells, such as Bacillus subtilis, the nucleoid is often found associated with mesosomes (Ryter, 1968). The nucleoid in these cells also often appears to be more condensed and to have a smaller volume than that found in Gram-negative cells and this may be partly due to a smaller amount of DNA. In both Gram-negative and Gram-positive cells the size of the nucleoid will increase somewhat during replication (Mason \& Powelson, 1956).

0022-1287/79/0000-8487\$02.00 (C) 1979 SGM

Vol. 111, No. 2 was issued 8 May 1979 

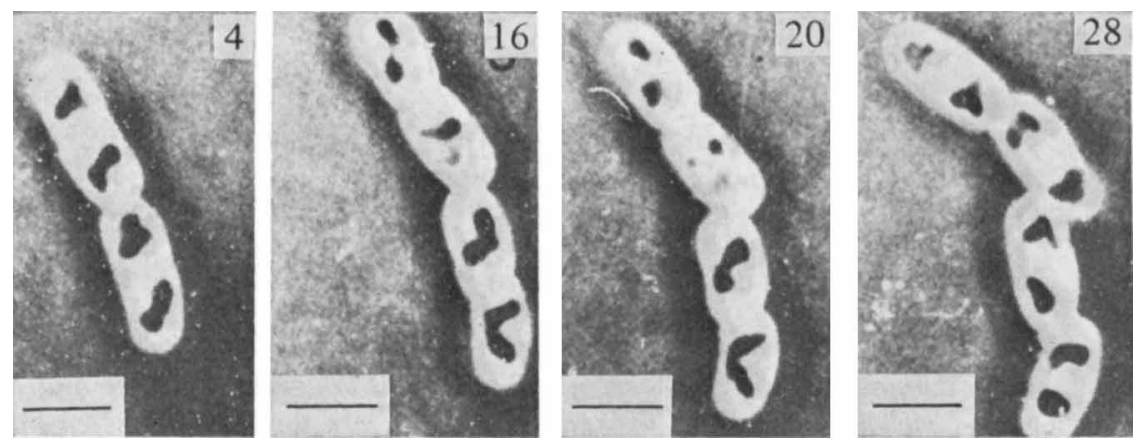

Fig. 1. Escherichia coli 61 growing in $20 \%$ gelatin brain-heart infusion medium. The ages of the cells were 4, 16, 20 and $28 \mathrm{~min}$, respectively. Bright high phase contrast microscopy was used. Bar markers represent $2 \mu \mathrm{m}$. From Mason \& Powelson (1956).

\section{Isolation and properties of the in vitro nucleoid}

The idea of trying to isolate the intact bacterial nucleoid has fascinated many, but it was not until approximately 8 years ago that reliable methods for this became available. Since that time, a number of research groups have been involved with various aspects of the nucleoid problem. Particularly important contributions to the field have been made by the research group headed by Dr David E. Pettijohn and Dr Abraham Worcel. Virtually all research in this area has been carried out using E. coli.

The main method used for preparation of the nucleoid was first developed by Stonington \& Pettijohn (1971). Numerous modifications of this procedure have since been published. Before describing this method it should be briefly mentioned that one can normally isolate two types of nuclear bodies - the cell envelope-associated nucleoid and the cell envelope-free nucleoid. The sedimentation coefficients for these two types of nucleoids are approximately $3200 \mathrm{~S}$ and $1600 \mathrm{~S}$, respectively (Pettijohn et al., 1973). For the preparation of the cell envelope-associated nucleoid, the cells are first suspended in $20 \%$ sucrose, then treated briefly with lysozyme-EDTA to weaken the cell wall. Following this treatment the cells are lysed with a mixture of two non-ionic detergents, Brij-58 and deoxycholate, in the presence of $1 \mathrm{M}-\mathrm{NaCl}$. The mixture is next layered on to a sucrose gradient $\left(10\right.$ to 30 or 10 to $\left.50_{\%}^{\%}, \mathrm{w} / \mathrm{v}\right)$ and centrifuged at $17000 \mathrm{~g}$ for $15 \mathrm{~min}$ in a Spinco SW40 Ti rotor. Alternative rotors and speeds may, of course, also be used. Further details are given by Korch et al. (1976). For the preparation of the cell envelope-free nucleoid, a longer lysozyme treatment and use of an ionic detergent such as Sarcosyl (Worcel \& Burgi, 1974) is usually required. The type of sucrose gradient and centrifugation time is the same as for the cell envelope-associated nucleoid. An example showing the banding pattern of the free nucleoid is shown in Fig. 3(a).

The properties of the two types of nucleoids have been investigated by many groups (see Pettijohn, 1976, for references). The cell envelope-associated nucleoid contains, in addition to DNA, large amounts of RNA, proteins, lipids and peptidoglycan (Korch et al., 1976; Pettijohn, 1976). The free nucleoid also contains RNA but little of the other non-DNA components found in the envelope-associated nucleoid. The major protein associated with the free nucleoid is the core RNA polymerase (Pettijohn, 1976). Up to $30 \%$ of the weight of the free nucleoid is made up of RNA and it has been shown that this RNA represents all the nascent RNA in the cell. It has been estimated that there are 1000 to 3000 RNA chains per nucleoid and approximately $40 \%$ of this RNA is rRNA (Pettijohn et al., 1970). In an exponentially growing culture the separation of two cells lags behind the synthesis of DNA and so the nucleoid from such cells grown in minimal medium contains between 1 and 2 chromosome equivalents of DNA (Hecht et al., 1975; Korch et al., 1976). The DNA in the isolated nucleoid is supercoiled, the amount of supercoiling being similar to that found 

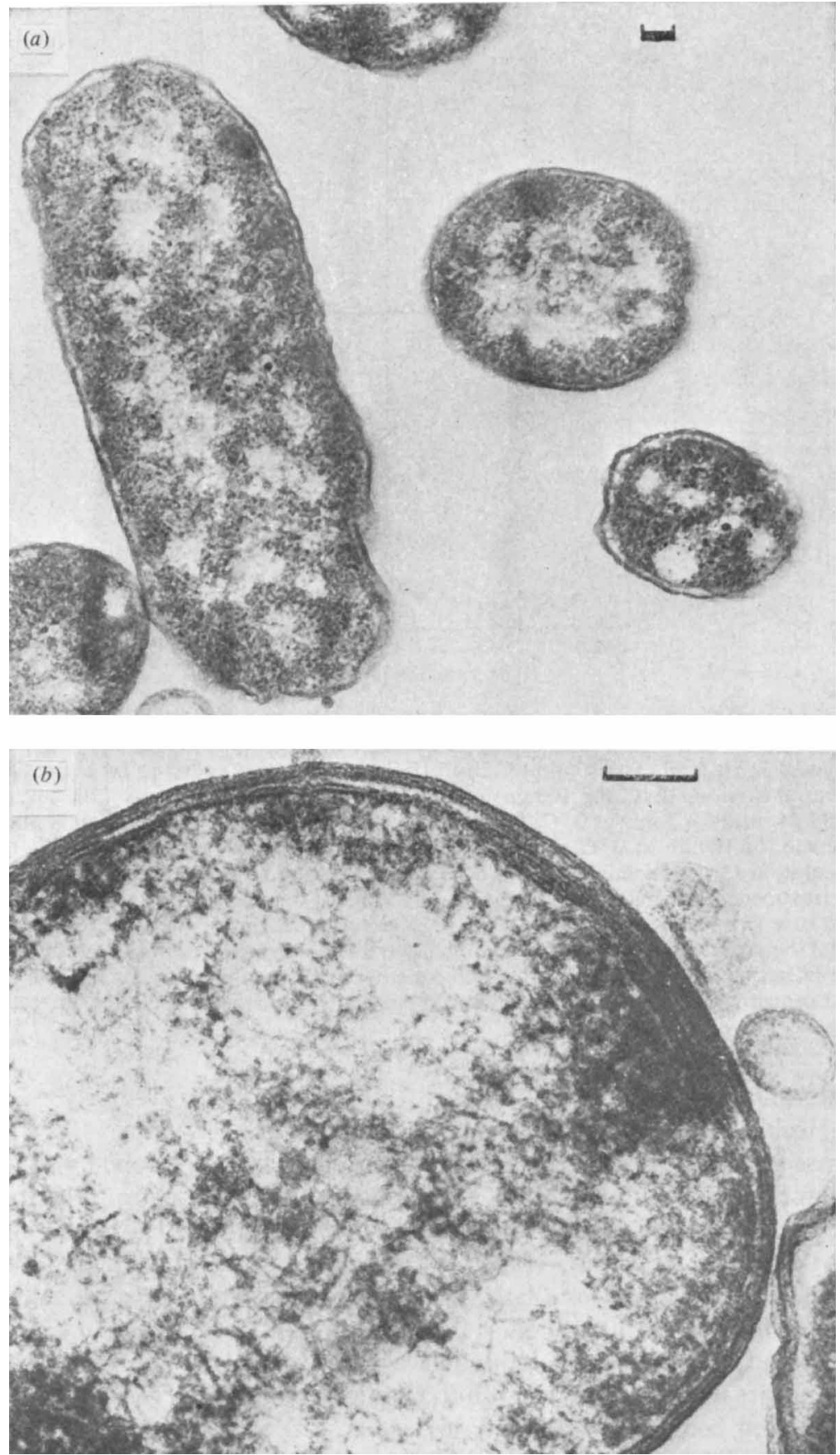

Fig. 2. Thin sections of E. coli K12 DG75 ( $\mathrm{F}^{-}$thy leu). The bacteria were grown in Herhey's minimal medium containing thymine and leucine and harvested in the exponential growth phase. They were immediately chilled and fixed with glutaraldehyde and osmium tetroxide, and then embedded and post-stained as described by Krüger \& Bloom (1974). Thin sections were examined in a Philips EM300 electron microscope. Bar markers represent $0 \cdot 1 \mu \mathrm{m}$. 


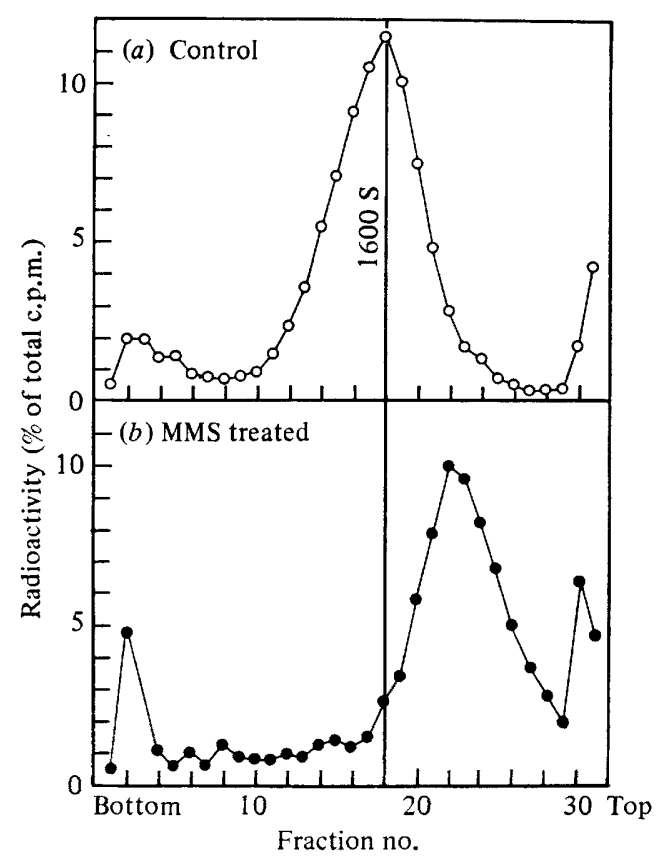

Fig. 3. Sedimentation patterns of envelope-free nucleoids from $E$. coli $\mathrm{K} 12 \mathrm{DG} 75\left(\mathrm{~F}^{-}\right.$thy leu). The bacteria were grown in minimal medium supplemented with thymine and leucine to an absorbance at $450 \mathrm{~nm}$ of $0 \cdot 3$. To $5 \mathrm{ml}$ of this culture, $5 \mu \mathrm{Ci}\left[{ }^{3} \mathrm{H}\right]$ thymidine was added to label the DNA; the mixture was shaken at $37^{\circ} \mathrm{C}$ for $10 \mathrm{~min}$, before chilling and centrifuging at $7500 \mathrm{rev} . \mathrm{min}^{-1}$ in a Sorvall SS-34 rotor for $5 \mathrm{~min}$ at $0^{\circ} \mathrm{C}$. The bacteria were then suspended in solution $\mathrm{A}$ and treated with lysozyme for $10 \mathrm{~min}$ at $0^{\circ} \mathrm{C}$ essentially as described by Korch et al. (1976). The detergent solution, solution C, contained $1 \%(\mathrm{w} / \mathrm{v})$ Sarcosyl in addition to Brij-58 and deoxycholate. The detergent treatment was carried out at $20^{\circ} \mathrm{C}$ for $10 \mathrm{~min}$. At the end of this period, the lysate was layered on to a $12 \mathrm{ml}$ sucrose gradient $[10$ to $30 \%(\mathrm{w} / \mathrm{v})$ in the buffer of Stonington \& Pettijohn (1971)], and then centrifuged at $4{ }^{\circ} \mathrm{C}$ for $2 \mathrm{~h}$ in a Sorvall HB-4 swing-out rotor at $10000 \mathrm{rev}$. min ${ }^{-1}$. In $(b)$, the bacteria had been treated with 25 mM-methyl methanesulphonate for $1 \mathrm{~h}$ at $37^{\circ} \mathrm{C}$ prior to the first centrifugation. The sedimentation coefficients have not been corrected for rotor speed effects.

for other naturally occurring DNAs such as $\lambda$ and SV40 DNA (Worcel \& Burgi, 1972; Pettijohn \& Hecht, 1973).

Nucleoid preparations have been examined in the electron microscope by various groups (Delius \& Worcel, 1973; Griffith, 1976; Kavenoff \& Bowen, 1976; Kavenoff \& Ryder, 1976). Figures 4 and 5 show some results obtained by Kavenoff and his coworkers (Kavenoff \& Bowen, 1976; Kavenoff \& Ryder, 1976) for the cell envelope-free and the cell envelopeassociated nucleoid. In both cases a large number of supercoiled loops extending from the centre is seen. In the free nucleoid (Fig. 4) the contour length of the longest loop is approximately $20 \mu \mathrm{m}$, and the number of loops has been estimated as approximately 140 . The central core appears to contain some bush-like material. When the grids were washed with RNAase this region became considerably less electron-dense, suggesting that most of the RNA in the nucleoid is in the central core. In the cell envelope-associated nucleoid (Fig. 5) a residual envelope is clearly visible.

In a recent study, Materman \& van Gool (1978) have shown that when the lysates are spread in a protein-free medium containing $1 \mathrm{M}-\mathrm{NaCl}$ and benzyldodecyldimethylammonium chloride, condensed bodies having a shape and dimensions similar to those of $E$. coli can be seen. The nucleoid is released from the cell as a beaded and branched fibre with an approximate diameter of $130 \mathrm{~nm}$. It probably consists of a hierarchy of supercoiled structures. 

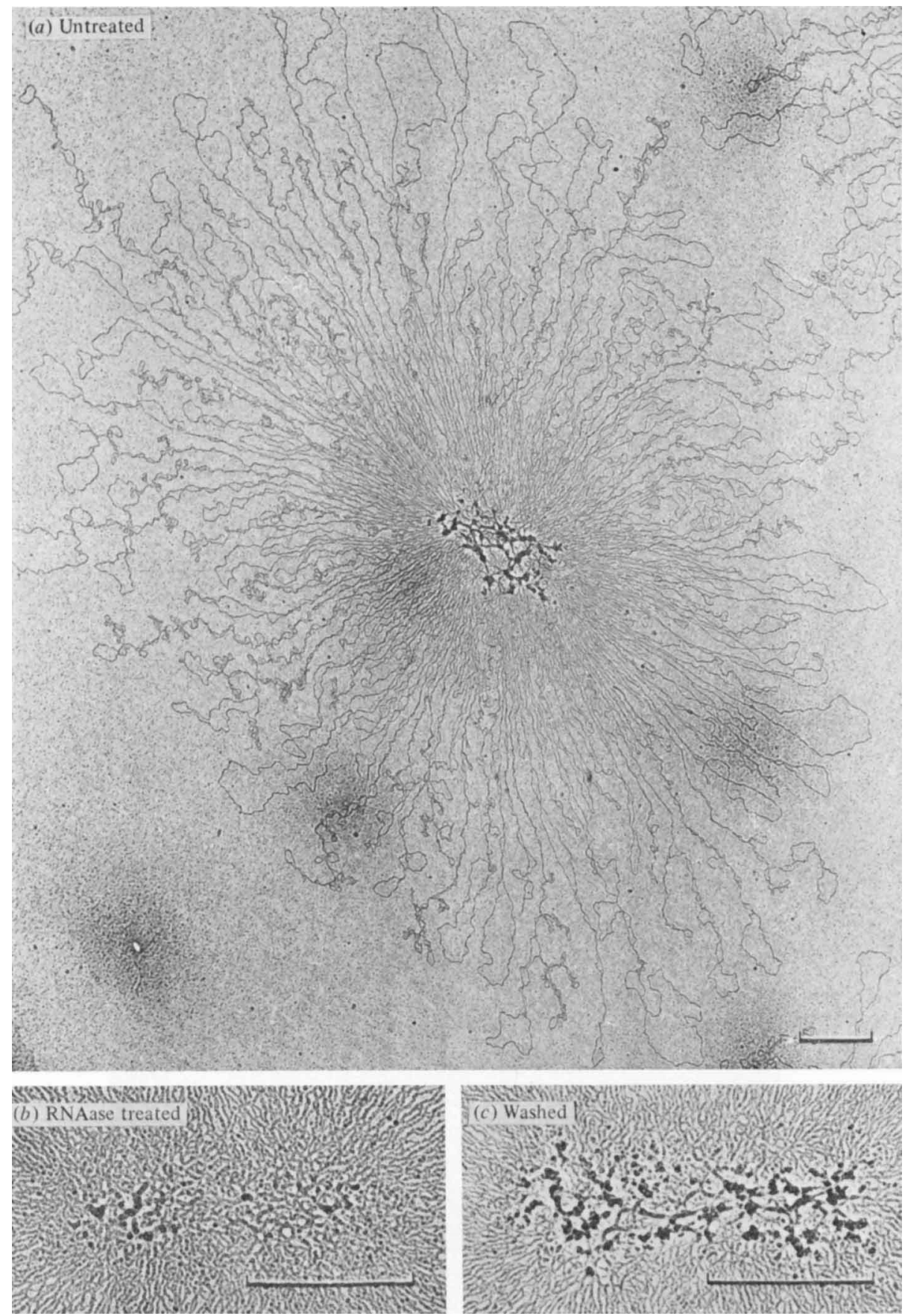

Fig. 4. Cell envelope-free nucleoid from $E$. coli 15 TAU-bar. The hypophase contained $0 \cdot 4 \mathrm{M}$ salt. The chromosome had $141 \pm 3$ loops and possibly a fork in the loop at about one o'clock. In $(b)$, the grid was washed with a solution of $40 \mu \mathrm{g}$ RNAase in $0.15 \mathrm{M}$-ammonium acetate for $2 \mathrm{~s}$. In $(c)$, the grid was washed with the control buffer. Bar markers represent $1 \mu \mathrm{m}$. From Kavenoff \& Bowen (1976). 


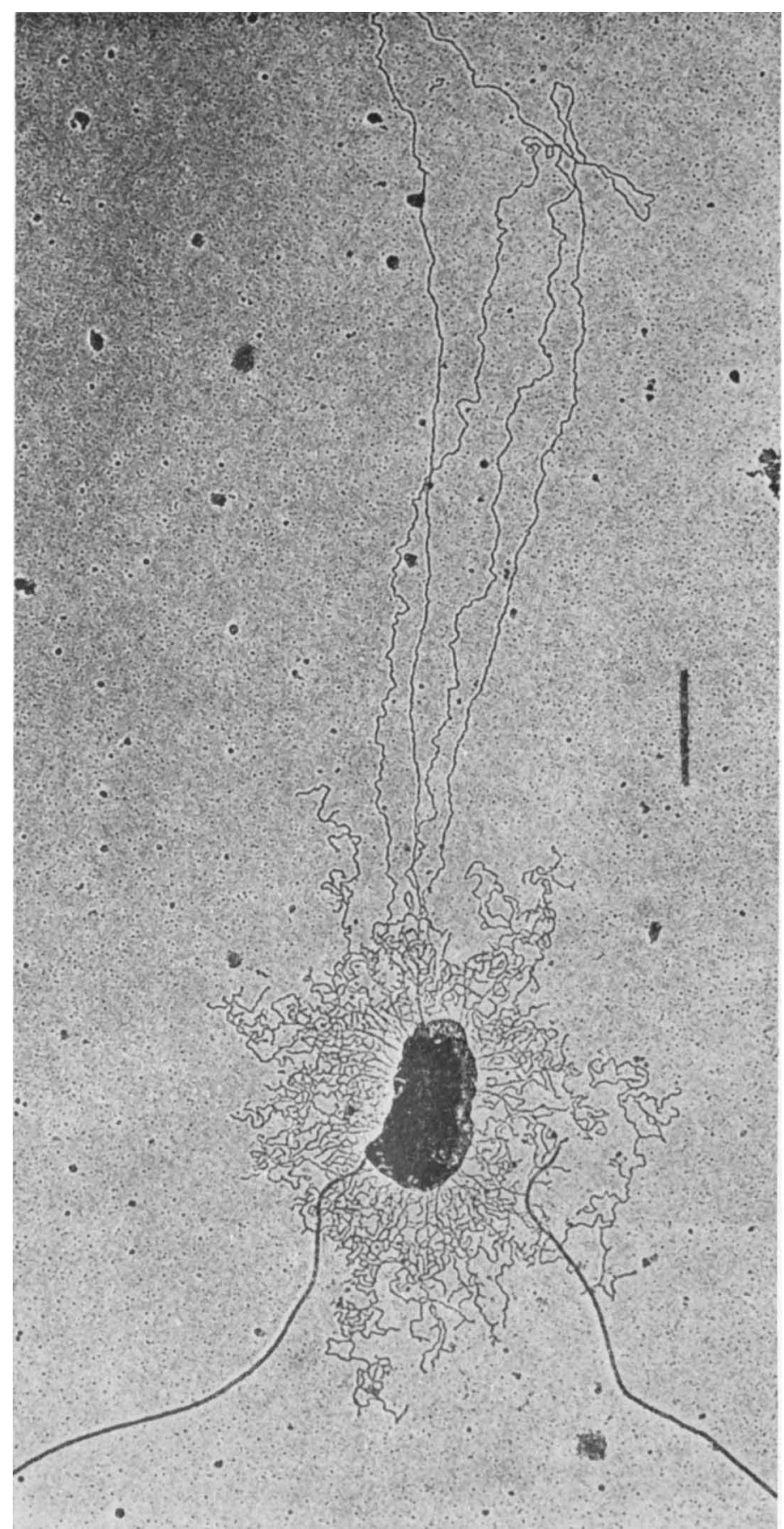

Fig. 5. Cell envelope-associated nucleoid of E. coli 15 TAU-bar. The contour length was $41 \mu \mathrm{m}$ (for two loops). Bar marker represents $1 \mu \mathrm{m}$. From Kavenoff \& Ryder (1976). 


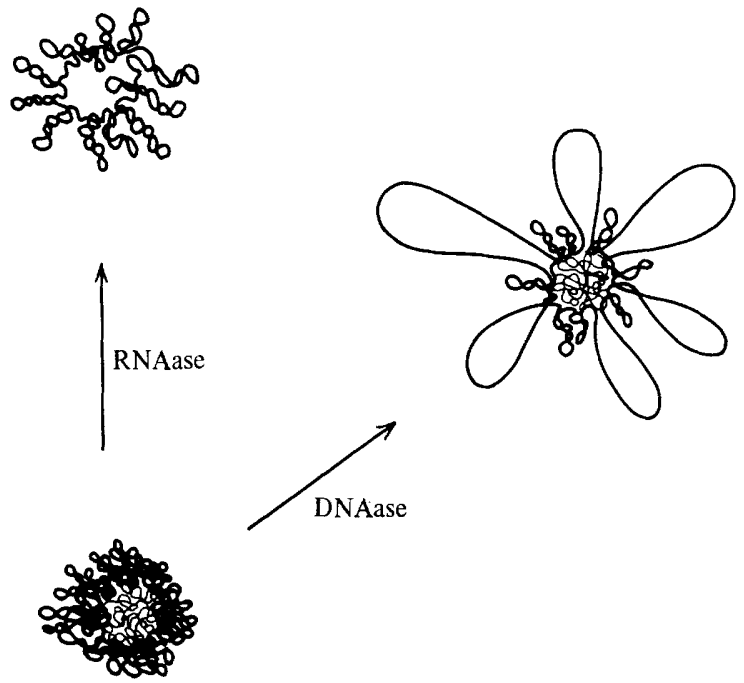

Fig. 6. A possible model of the isolated bacterial nucleoid.

The influence of RNAase and DNAase on the structure of the nucleoid has been investigated principally by Pettijohn \& Hecht (1973) and by Worcel \& Burgi (1972). Treatment with either RNAase or DNAase causes a dramatic decrease in the sedimentation coefficients for the two types of nucleoids and an increase in the viscosity of the lysate. The effective volume of the nucleoid increases during such a treatment. RNAase destroys the core RNA, and on extensive treatment the sedimentation coefficient of the free nucleoid decreases from $1600 \mathrm{~S}$ to approximately 400 to $500 \mathrm{~S}$. Treatment with DNAase leads to a loss of supercoiling, resulting in an extension of the DNA loops. The sedimentation coefficient of the completely relaxed chromosome has been estimated to be $130 \mathrm{~S}$. Proteases may also, under certain conditions, cause unfolding of the free nucleoid. However, there is conflicting evidence as to whether proteins stabilize the free nucleoid (Pettijohn, 1976).

One important feature of the nucleoid structure is that it is stabilized by high concentration of salts such as $\mathrm{NaCl}$. The nucleoid structure rapidly disintegrates if the salt concentration is lowered. Polyamines may be used instead of salt as counter ions (Flink \& Pettijohn, 1975).

Changes in the physiological conditions of the cell, such as by starvation for an amino acid, may also cause a decrease in the sedimentation coefficient of the nucleoid isolated from a stringent strain of E. coli, but not from a relaxed strain (Övrebö \& Korch, 1978). Nucleoids isolated from cells grown in the presence of chemicals such as rifampicin (Dworsky \& Schaechter, 1973; Pettijohn \& Hecht, 1973), mitomycin C and methyl methanesulphonate (Kleppe \& Lossius, 1978) have greatly altered sedimentation properties. For example rifampicin inhibits initiation of RNA synthesis and thus the amount of nascent RNA involved in stabilization of the nucleoid structure is sharply reduced in the presence of this drug, with a concomitant decrease in its sedimentation coefficient. In the presence of the mutagens mitomycin $\mathrm{C}$ and methyl methanesulphonate, extensive nicking of the chromosome occurs due to the influence of repair enzymes, resulting in a loss of supercoiling. An example of the effect of methyl methanesulphonate is shown in Fig. 3(b). Treatment with this mutagen for $1 \mathrm{~h}$ results in a decrease in the sedimentation coefficient from $1600 \mathrm{~S}$ to approximately $700 \mathrm{~S}$.

Models for the structure of the free isolated nucleoid have been suggested by Worcel \& Burgi (1972) and by Pettijohn et al. (1973). A central feature of these models is that the nucleoid structure consists of a number of separate supercoiled loops held together by RNA molecules. The loops represent separate domains of supercoiling so that nicking of a par- 
ticular domain results in the relaxation of that domain only. Figure 6 shows a slightly different model, which also takes into account the fact that most of the RNA is found in the centre of the nucleoid and that RNA-RNA as well as RNA-DNA interactions may be of importance in maintaining its structure.

\section{Possible artefacts incurred during isolation of the nucleoid}

A fundamental question that still remains to be satisfactorily answered is whether the structure of the isolated nucleoid proposed above resembles that of the nucleoid in vivo. It has been pointed out by Kavenoff \& Bowen (1976) and also by Pettijohn (1976) that artefacts may result from the use of high concentrations of detergents and salts. The stabilization of the nucleoid by RNA could, in part, be due to the aggregation of nascent RNA chains. It is known that mRNA will aggregate in high salt concentrations (Boedtker, 1968). Moreover, rRNA and mRNA easily form complexes in high concentrations of salt (Asano, 1965; Marcot-Queiroz \& Monier, 1965). A portion of the RNA molecules may also exist in a double-stranded RNA-DNA hybrid form in the nucleoid. Richardson (1975) has shown that such hybrids are easily formed when a reaction mixture containing RNA polymerase and supercoiled DNA is treated with detergents and high concentrations of salt, i.e. conditions similar to those used for the isolation of the nucleoid. Stabilization of DNA-RNA hybrids at the 3 '-hydroxyl end of the RNA is thermodynamically favoured under such conditions, leaving the $5^{\prime}$ end of the RNA molecule essentially single-stranded. This part of the RNA could then engage in complexes with other RNA or DNA molecules. Thus, the separate DNA loops may represent areas on the chromosome where relatively little transcription occurs, whereas the transcriptionally active areas are situated in the centre of the isolated nucleoid.

It has been known for some time that there is a tight coupling between transcription and translation in E. coli (see Lewin, 1974, for references) and, moreover, the rates of transcription and translation are approximately the same. The elegant electron microscopic studies of Miller et al. (1970) also clearly show multiple copies of RNA being made and translated on single genes. Autoradiographic studies of $E$. coli cells have shown that RNA synthesis occurs primarily in the cytoplasm and along the membranes and not in the nucleoid centre (Ryter \& Chang, 1975). It appears, therefore, that the location of most of the RNA chains in the centre of the isolated nucleoid has been inverted from that in the intact cell where the RNA chains are found mainly at the outer regions of the nucleoid or attached to the cytoplasmic membranes.

\section{A possible structure of the in vivo nucleoid}

On the basis of gene product function and location one may in general distinguish between two types of mRNA molecules, namely those that code for cytoplasmic components and those that code for proteins and enzymes which are components of the cytoplasmic membrane, periplasmic space and the outer membrane. A number of results now suggest that the cytoplasmic group of proteins are synthesized in the cytoplasm, whereas the membrane group of proteins are made on the inner cytoplasmic membrane (Schlesinger, 1968; Costerton et al., 1974; Yamamoto \& Lampen, 1976; Inouye \& Beckwith, 1977; Inouye et al., 1977; Silhavy et al., 1977). Thus for an accurate description of the nucleoid structure in vivo one must, due to the tight coupling between transcription and translation, also take into account the protein-synthesizing machinery and attachment to membranes. During the isolation of the nucleoid, the ribosomes will dissociate from the mRNA due to the presence of the chelating agent EDTA and due to the high concentration of salts and detergents. A schematic drawing of the nucleoid structure in vivo in a cell containing one chromosomal equivalent, prior to replication, is presented in Fig. 7. The DNA in the centre of the nucleoid is thought to be tightly packaged and to have a high degree of supercoiling, 


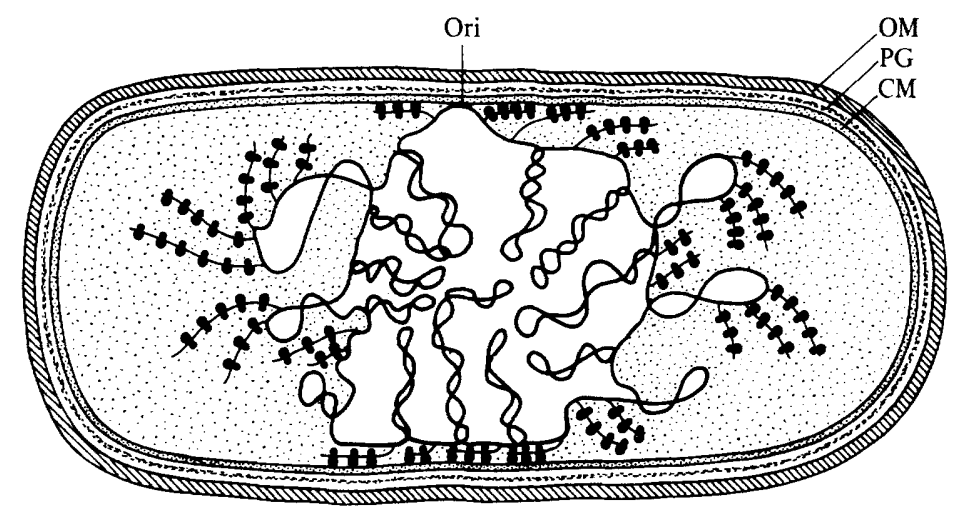

Fig. 7. A schematic model of the organization of the nucleoid in vivo in E. coli. Ori, Origin of replication; OM, outer membrane; PG, peptidoglycan; CM, cytoplasmic membrane.

whereas the area where RNA synthesis takes place is more loosely packaged. In general, the RNA molecules being made are thought to project out into the cytoplasm or to be bound via ribosomes to the inner membrane (Ryter \& Chang, 1975). There are probably multiple mRNA-ribosomal attachment sites, with the mRNA also being bound to the chromosome via RNA polymerase. A somewhat similar model of the nucleoid has been suggested by Ryter \& Chang (1975).

Supercoiling and tight packaging of DNA is necessary for many important cellular processes, such as the separation of the two daughter chromosomes and an ordered transcription mechanism (Champoux, 1978). It is difficult to see how the normal control mechanisms could function in the cell if the chromosome was not supercoiled. The recent discovery of the DNA gyrase enzyme also emphasizes that the process of supercoiling is important for the cell (Gellert et al., 1976). This enzyme utilizes ATP as energy to introduce negative superhelical turns into the chromosome. Thus, it appears that supercoiling is to a large extent also dependent on the metabolic state of the cell.

The model of the in vivo nucleoid envisages that there are supercoiled regions or domains, which might be stabilized by certain proteins such as the histone-like protein described by Rouvière-Yaniv \& Gros (1975). This protein is not found in the in vitro isolated nucleoid as it dissociates from the DNA at a salt concentration of approximately $0.4 \mathrm{M}$. Stabilization by certain specific RNA molecules cannot, of course, be ruled out, but the majority of the RNA molecules protrude into the cytoplasm or along the membranes.

Earlier microscopic studies, such as those shown in Fig. 1, have revealed that as the replication process proceeds the new daughter chromosomes appear to be tightly packaged from the start. At the termination of the replication there are two separate nucleoid bodies in the cell. It should be possible to detect similar nuclear bodies in the isolated nucleoid preparations by use of, for example, the scanning electron microscope. At present there appears to be no evidence to suggest that the nucleoid is more tightly packaged at the time of cell division than earlier in the cell cycle, as is observed for eukaryotic cells.

\section{Attachment of the nucleoid to the membrane}

A more detailed review of the association of the chromosome with the cell envelope has previously been published (Leibowitz \& Schaechter, 1975).

The chromosome can be isolated associated with the cell envelope throughout the cell cycle. An earlier study suggesting that it became detached at the end of its replication (Worcel \& Burgi, 1974) has been shown to be due to artefacts (Ryder \& Smith, 1975; Korch et al., 1976). A recent study of the cell envelope-associated nucleoid prepared in a low concentration of salt and in the presence of spermidine suggests that random DNA 
sequences rather than specific ones are responsible for the majority of the DNA-membrane interactions (Drilica et al., 1978). S1 nuclease has also been used to probe the interactions between the chromosome and the cell membrane (Abe et al., 1977). Single-stranded regions of the DNA seem to bind more tightly than the double-stranded structures. Approximately 20 binding sites were detected per cell by this technique. The attachment site of the chromosome at or near the origin of replication was found to be different from the other binding sites. However, this technique does not prove directly that most of the associations occur via single-stranded DNA regions. There could be other types of associations resulting in a partial unwinding of the DNA near the binding site as discussed below. It is likely that the attachment of the chromosome to the membrane may take place by two different types of linkages, namely one specific protein-mediated linkage and a number of chromosome-RNA polymerase-mRNA-ribosomes association sites. These two possibilities are discussed below in more detail.

For $E$. coli, results have been presented which strongly suggest that there is a unique attachment site at or close to the origin of replication of the chromosome (Fielding \& Fox, 1970; Parker \& Glaser, 1974; Craine \& Rupert, 1978; Nicolaidis \& Holland, 1978). There are conflicting results regarding the possible association between the replication forks and the membrane (for references, see Leibowitz \& Schaechter, 1975). In the case of the origin of replication, a specific protein may be involved in this binding(Craine \& Rupert, 1978; Portalier $\&$ Worcel, 1976). Such a protein must recognize and bind to specific base sequences or tertiary structures of the chromosome only found at or close to the origin of replication. In addition it must also possess a hydrophobic part which intrudes into the membrane.

With regard to the RNA polymerase-mRNA-ribosome-mediated linkages, Dworsky \& Schaechter (1973) have presented evidence, using the M-band technique, that there may be at least 20 associations per cell. The majority of the ribosomes found in such complexes are bound to the DNA (Tremblay et al., 1969). When rifampicin, an initiation inhibitor of RNA polymerase, was added to $E$. coli cells the number of attachment sites decreased drastically, as expected. The type of mRNA involved in such an association could be mRNA coding for membrane or periplasmic proteins. As mentioned above, there are now many examples showing that such proteins are synthesized on the inner membrane. It has recently been estimated there are approximately 170 different membrane proteins in E. coli (Sato et al., 1977) and, furthermore, these make up a major part of the total protein of the cell. We suggest that, as a general rule, such proteins are synthesized on the inner cytoplasmic membrane and that at least in the case of some, most likely the major proteins, associations of the chromosome to the membrane occur via RNA polymerase, mRNA and ribosomes. A schematic view of the association site with the membrane is shown in Fig. 8. In this particular example a periplasmic or outer membrane protein is being made. A somewhat similar model has been presented by Costerton et al. (1974). The specificity of attachment to the membrane resides in the amino acid composition of the $N$-terminal end of the protein being synthesized. This $N$-terminal end is thought to be highly hydrophobic in nature and serves as an anchoring point in the membrane. Upon completion of the synthesis of the protein this end of the peptide chain is probably cut off by specific proteases. The energetics of the extrusion of the peptide chain through the membrane is still not fully understood (Smith et al., 1978). This scheme resembles the signal hypothesis proposed by Blobel \& Dobberstein (1975) for eukaryotic cells.

\section{Gross transcription control}

Two processes might be important with regard to gross transcription control. First, it is clear that the replication machinery requires extensive local unfolding of the tightly folded structure surrounding the replication forks. Thus, the whole chromosome will eventually have been sequentially opened up during the replication period. The inducement of supercoiling into the new daughter chromosomes may be an important factor in this process. Other 


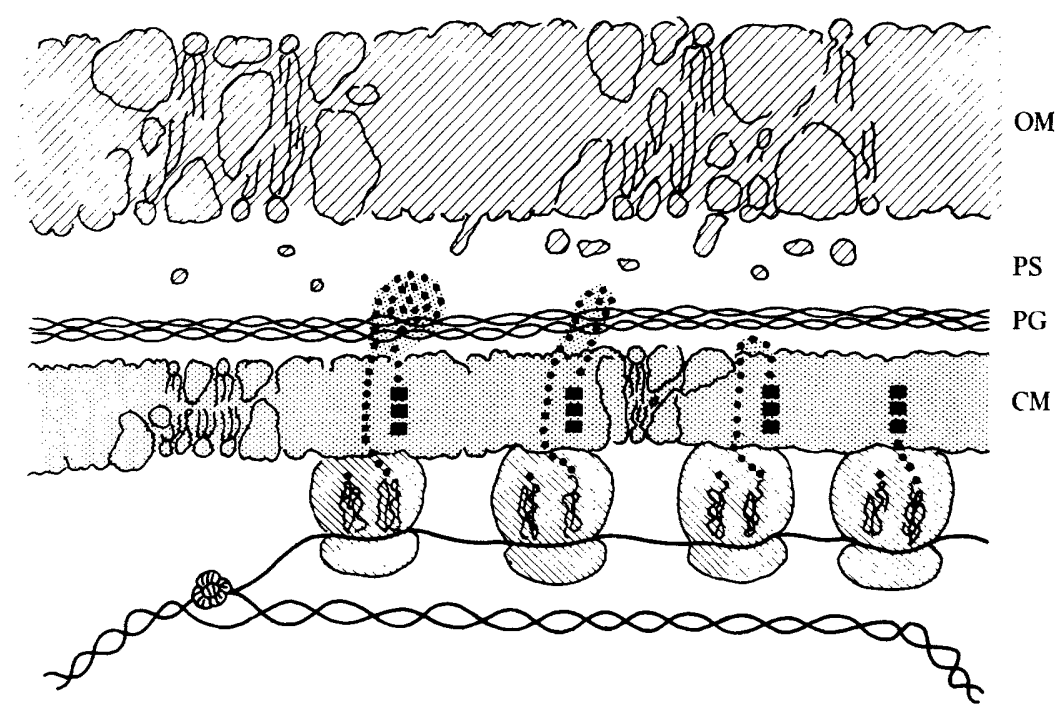

Fig. 8. A schematic model showing the attachment of the DNA to the membrane via RNA polymerase, mRNA and ribosomes. OM, Outer membrane; PS, periplasmic space; PG, peptidoglycan; $\mathrm{CM}$, cytoplasmic membrane. The symbols indicate the hydrophobic $N$-terminal part of the peptide chain.

regions not connected with the replication forks may also become available for transcription during this event.

The second type of gross control of transcription is related to the association of the chromosome with the membrane. RNA polymerase may diffuse to the outer regions of the nucleoid and transcription of some membrane protein genes may start. Eventually, through changes in the structure of the nucleoid, the $N$-terminal end of the peptide being made from mRNA will become embedded in the cytoplasmic membrane. Multiple association sites of this type put a restriction on the nucleoid with regard to packaging. Certain regions will of necessity be more open and thus more accessible to RNA polymerase. As the cell membrane grows it may also help to open up new regions on the chromosome. The spacing of the genes for membrane proteins might then become important. It is tempting to suggest, therefore, that the arrangement of genes on the chromosome is not accidental, but is the result of evolution and involvement of a number of carefully controlled processes. In this regard it is interesting to note that the known gene loci in $E$. coli are clustered on the genetic map (Bachmann et al., 1976). Moreover, the known gene loci for membrane proteins are also found to be clustered around the chromosome in approximately 15 clusters (Kleppe, unpublished). The latter number agrees well with the number of association sites between the chromosome and the membrane 'as determined by different techniques (Dworsky \& Schaechter, 1973; Abe et al., 1977). The genetic map also contains large so-called silent regions and these could constitute highly supercoiled areas on the chromosome. They may also include copies of redundant genes.

\section{Concluding remarks}

The structure of the in vivo nucleoid in bacteria may be somewhat different from that normally proposed for the in vitro nucleoid. A central feature of both models, however, is the supercoiling which is necessary for many processes. In times of energy starvation and repair, the supercoiling may be less dense than when the cells are growing normally. The structure envisaged is not static but dynamic in nature, and capable of interacting with other macromolecules as well as responding to changes in the metabolic state of the cell. In 
order to give an accurate account of the structure within the cell, association with the protein-synthesizing machinery as well as the membranes must also be taken into consideration.

There are still a number of unsolved questions with regard to the nucleoid structure. For example, what is the exact nature of the packaging of the chromosome? The results of Materman \& van Gool (1978) suggest that the structure consists of a hierarchy of superhelices. Which proteins and RNA species are important for the packing? What is the exact nature of the binding sites to the membranes? What is the function of the so-called silent regions on the chromosome? Hopefully, future research should be able to shed some light on these important questions.

We are most grateful to Dr P. G. Krüger for taking the electron microscope photographs of E. coli and to $\mathrm{Dr}$ C. Korch for criticism of the manuscript. Part of this work was supported by the Norwegian Research Council for Science and Humanities.

\section{REFERENCES}

Abe, M., Brown, C., Hendrickson, W. G., Boyd, D. H., Clifford, P., Cote, R. H. \& Schaechter, M. (1977). Release of Escherichia coli DNA from membrane complexes by single-strand endonucleases. Proceedings of the National Academy of Sciences of the United States of America 74, 2756-2760.

ASANO, K. (1965). Size heterogeneity of $\mathrm{T}_{2}$ messenger RNA. Journal of Molecular Biology 14, 71-84.

BachmanN, B. J., Low, K. B. \& TAYlor, A. L. (1976). Recalibrated linkage map of Escherichia coli K-12. Bacteriological Reviews 40, 116-167.

Bisset, K. A. (1970). The Cytology and Life-history of Bacteria, 3rd edn. Edinburgh and London: Livingstone.

Bisset, K. A. \& Whitby, H. (1978). Demonstration of nuclear and cellular division in Bacillus cereus by epifluorescent microscopy. Journal of General Microbiology 107, 231-234.

Blobel, G. \& Dobberstein, B. (1975). Transfer of proteins across membranes. I. Presence of proteolytically processed and unprocessed nascent immunoglobulin light chains on membrane-bound ribosomes of murine myeloma. Journal of Cell Biology 67, 835-851.

BOEDTKER, H. (1968). Molecular weight and conformation of RNA. Methods in Enzymology 12B, $429-460$.

Champoux, J. J. (1978). Proteins that affect DNA conformations. Annual Review of Biochemistry 47, 449-479.

Costerton, I. W., Ingram, I. M. \& Cheng, K. J. (1974). Structure and function of the cell envelope of gram-negative bacteria. Bacteriological Reviews 38, 87-110.

Craine, B. L. \& RuPert, C. S. (1978). Identification of a biochemically unique DNA-membrane interaction involving the Escherichia coli origin of replication. Journal of Bacteriology 134, 193-199.

Delius, H. \& WorCel, A. (1973). Electron microscopic visualization of the folded chromosome of Escherichia coli. Journal of Molecular Biology 82, 107-109.

Drilica, K., Burgi, E. \& Worcel, A. (1978). Association of the folded chromosome with the cell envelope of Escherichia coli: nature of the membrane-associated DNA. Journal of Bacteriology 134, 1108-1116.

Dworsky, P. \& SCHAECHTER, M. (1973). Effect of rifampicin on the structure and membrane attachment of the nucleoid of Escherichia coli. Journal of Bacteriology 116, 1364-1374.

Fielding, P. \& Fox, C. F. (1970). Evidence for stable attachment of DNA at the replication origin of Escherichia coli. Biochemical and Biophysical Research Communications 41, 157-162.

Flink, I. \& Pettijohn, D. E. (1975). Polyamines stabilize DNA folds. Nature, London 253, 6263.

Gellert, M., Mizuuchi, T., O’Dea, M. H. \& NASH, H. (1976). DNA gyrase: an enzyme that that introduces superhelical turns into DNA. Proceedings of the National Academy of Sciences of the United States of America 73, 3872-3876.

GrIFFITH, J. (1976). Visualization of procaryotic DNA in a regularly condensed chromatin-like fiber. Proceedings of the National Academy of Sciences of the United States of America 73, 536-567.

Hecht, R., Taggert, R. \& Pettijohn, D. (1975). Size of DNA content of purified $E$. coli nucleoids observed by fluorescence microscopy. Nature, London 253, 60-61.

INOUYE, H. \& BeCKWITH, J. (1977). Synthesis and processing of an Escherichia coli alkaline phosphatase precursor in vitro. Proceedings of the National Academy of Sciences of the United States of America 74, 1440-1444.

Inouye, S., Wang, S., Sekizawa, J., Halegova, S. \& INOUYE, M. (1977). Amino acid sequence for the peptide extension on the prolipoprotein of the Escherichia coli outer membrane. Proceedings of the National Academy of Sciences of the United States of America 74, $1004-1008$.

Kavenoff, R. \& Bowen, B. C. (1976). Electron microscopy of membrane-free folded chromosomes from Escherichia coli. Chromosoma 59, 89-101.

Kavenoff, R. \& RydeR, O. A. (1976). Electron microscopy of membrane-associated folded 
chromosomes of Escherichia coli. Chromosoma 55, 13-25.

KLEPPE, K. \& Lossius, I. (1978). Influence of mutagens on the nucleoid structure of the chromosome in Escherichia coli. 78th Annual Meeting of American Society for Microbiology, Las Vegas, pp. 125.

KorCH, C., Övrebö, S. \& KLepPe, K. (1976). Envelope-associated folded chromosomes from Escherichia coli : variations under different physiological conditions. Journal of Bacteriology 127, 904-916.

Krüger, P. G. \& Bloom, G. (1974). Structural features of histamine release in rat peritoneal mast cells. International Archives of Allergy and Applied Immunology 46, 740-752.

Leibowitz, P. J. \& Schaechter, M. (1975). The attachment of the bacterial chromosome to the cell membrane. International Review of Cytology 41, $1-28$.

LewIN, B. (1974). Gene Expression-1, pp. 378-410. London and New York: John Wiley.

MARCOT-QueIroz, J. \& Monier, R. (1965). Interactions between RNAs from Escherichia coli ribosomes. Journal of Molecular Biology 14, 490-505.

Mason, D. J. \& Powelson, D. M. (1956). Nuclear division as observed in live bacteria by a new technique. Journal of Bacteriology 71, 474-479.

Materman, E. C. \& van Gool, A. P. (1978). Compact Escherichia coli nucleoids in a highly supercoiled conformation. Journal of Bacteriology 135, 703-706.

Miller, O. L., Hamkalo, B. A. \& Thomas, C. A. (1970). Visualization of bacterial genes in action. Science 169, 392-395.

Nicolaidis, A. A. \& Holland, I. B. (1978). Evidence for specific association of the chromosomal origin with outer membrane fractions isolated from Escherichia coli. Journal of Bacteriology 135, 178-189.

ÖVReBö, S. \& KorCH, C. (1978). Bacterial nucleoid structure after inhibition of DNA replication: the role of RNA synthesis. In DNA Synthesis: Present and Future, pp. 439-445. Edited by I. Molineux \& M. Kohiyama. New York and London: Plenum Press.

Parker, D. L. \& Glaser, D. A. (1974). Chromosomal sites of DNA-membrane attachment in Escherichia coli. Journal of Molecular Biology 87, 153-168.

Pettijohn, D. E. (1976). Procaryotic DNA in nucleoid structure. CRC Critical Reviews in Biochemistry 4, 175-202.

Petrijohn, D. E. \& Hecht, R. (1973). RNA molecules bound to the folded bacterial genome stabilize DNA folds and segregate domains of supercoiling. Cold Spring Harbor Symposia on Quantitative Biology 38, 31-42.

Pettijohn, D. E., Clarkson, K., Kossman, C. \& Stonington, O. (1970). Synthesis of ribosomal RNA in a protein-DNA complex isolated from bacteria: a comparison of ribosomal RNA synthesis in vitro and in vivo. Journal of Molecular Biology 52, 281-300.

Pettijohn, D. E., Hecht, R. M., Stonington O. G. \& Stamato, T. D. (1973). Factors stabilizing DNA folding in bacterial chromosomes. In
DNA Synthesis in vitro, pp. 145-163. Edited by R. D. Wells \& R. B. Inman. Lancaster: Medical and Technical Publishing Co.

Portalier, R. \& Worcel, A. (1976). Association of the folded chromosome with the cell envelope of $E$. coli: characterization of the proteins at the DNA-membrane attachment site. Cell 8, 245-255.

Richardson, J. P. (1975). Attachment of nascent RNA molecules to superhelical DNA. Journal of Molecular Biology 98, 565-579.

RouviÈre-YANIV, J. \& Gros, F. (1975). Characterization of a novel low-molecular weight DNAbinding protein from Escherichia coli. Proceedings of the National Academy of Sciences of the United States of America 72, 3428-3442.

RyDER, O. A. \& SMITH, D. W. (1975). Properties of membrane-associated folded chromosomes of $E$. coli related to initiation and termination of DNA replication. Cell 4, 337-345.

RYTER, A. (1968). Association of the nucleus and the membrane of bacteria: a morphological study. Bacteriological Reviews 32, 39-54.

RYTER, A. \& CHANG, A. (1975). Localization of transcribing genes in the bacterial cell by means of high resolution autoradiography. Journal of Molecular Biology 98, 797-810.

Sato, T., Ito, K. \& Yura, T. (1977). Membrane proteins of Escherichia coli K-12: two-dimensional polyacrylamide gel-electrophoresis of inner and outer membranes. Europecin Journal of Biochemistry 78, 557-567.

Schlesinger, H. J. (1968). Secretion of alkaline phosphatase subunits by spheroblasts of Eschericha coli. Journal of Bacteriology 96, 727-733.

Silhavy, T. J., Shuman, H. A., Beckwith, J. \& SchWARTZ, M. (1977). Use of gene fusion to study outer membrane protein localization in Escherichia coli. Proceedings of the National Academy of Sciences of the United States of America 74, 5411-5415.

Smith, W. P., TaI, P. C. \& Davis, B. D. (1978). Nascent peptide as sole attachment of polysomes to membranes in bacteria. Proceedings of the National Academy of Sciences of the United States of America 75, 814-817.

Stonington, O. G. \& Petrijohn, D. E. (1971). The folded genome of Escherichia coli isolated in a protein-DNA-RNA complex. Proceedings of the National Academy of Sciences of the United States of America 68, 6-9.

Tremblay, G. Y., Daniels, M. J. \& Schaechter, M. (1969). Isolation of a cell membrane-DNAnascent RNA complex from bacteria. Journal of Molecular Biology 40, 65-76.

WorCel, A. \& Burgi, E. (1972). On the structure of the folded chromosome of Escherichia coli. Journal of Molecular Biology 71, 127-147.

Worcel, A. \& Burgi, E. (1974). Properties of a membrane-attached form of the folded chromosome of Escherichia coli. Journal of Molecular Biology 82, 91-105.

YAMAMoto, S. \& LAMPEN, J. O. (1976). Membrane penicillinase of Bacillus licheniformis 749/c: sequence and possible repeated tetrapeptide structure of the phospholipopeptide region. Proceedings of the National Academy of Sciences of the United States of America 73, 1457-1461. 